\title{
Fragile $X$ screening for FRAXA and FRAXE mutations using PCR based studies: Results of a five year study
}

\author{
Madhumita Roy Chowdhury, Madhulika Kabra, Deepti Sharma*, Deepika Singh*, Anjali Dabral*, B. K. Thelma*, \\ Veena Kalra \\ Genetics Division, Departments of Pediatrics, *Genetics, University of Delhi, South Campus, All India Institute of Medical Sciences, \\ New Delhi - 110 029, India
}

BACKGROUND: Fragile $X$ syndrome is the most common cause of inherited $X$-linked mental retardation. It is due to a mutation in a gene on $\mathrm{X}$ chromosome leading to hyperexpansion of a trinucleotide repeat sequence. The two most common Fragile sites with clinical significance are FRAXA at $X q^{27.3}$ comprising CGG repeat and a more distal FRAXE associated with amplification of a GCC repeat, located at $\mathrm{Xq}^{28}$. The frequency of occurrence of Fragile $X$ syndrome is estimated to be 1/4000 male births. Screening of referrals for the mutations associated with the Fragile $X$ syndrome constitutes a significant workload in many genetic laboratories.

AIMS: The aim of the present study was to establish the use of PCR based simple and rapid method of initial screening of samples, so that only a minority of samples tested positive with the above methods need to be screened by Southern blotting which is more time consuming and involves use of radioactive material.

MATERIALS AND METHODS: Study includes 294 patients with mental retardation. DNA extracted from blood was used for simultaneous amplification of the triplet repeat sequences at the FRAXA and FRAXE loci. Secondly samples from females were analyzed for heterozygosity of normal FRAXA allele. For confirmation of the presence of an expanded FRAXA allele in all the male positive cases, Southern blot hybridization was carried out. PCR based assay was done to detect methylation of the $\mathrm{CpG}$ island upstream of the FMR-1 gene.

RESULTS: Out of the 294 cases 23 (7.8\%) were found to be having full mutation (FM) for FRAXA (21 males, 1 female \& 1 male with mosaic FM/PM) and 13 females as having premutation (PM). All these 36 cases were confirmed by Southern blotting using appropriate probes. Among the females the heterozygosity for FRAXA allele was found to be $46 \%$.

CONCLUSION: Non-radioactive PCR methods are efficient and rapid test for intial screening of samples for the presence of FRAXA and FRAXE mutations. Since a large majority of referrals do not have Fragile $X$, this economical and reliable method reduces the number of samples needing Southern blotting.

Key words: Fragile X syndrome, trinucleotide repeat, methylation, pre-mutation, full mutation, heterozygosity, polymerase chain reaction.

\section{Introduction}

Fragile $\mathrm{X}$ syndrome is an $\mathrm{X}$-linked semi-dominantly inherited disorder with reduced penetrance and does not follow a classical Mendelian pattern of inheritance. It represents the most frequent form of inherited severe cognitive deficit. ${ }^{[1]}$ Males as well as females can be affected, although the latter to a lesser extent. In addition, both males and females can be unaffected carriers. Among the western populations the frequency of fragile $X$ syndrome is estimated to be $1 / 4000$ births and $1 / 8000$ female births. ${ }^{[2]}$ Few studies in Indian population show the frequency of Fragile $X(A)$ syndrome among idiopathic mentally retarded (MR) males as approximately $7 \% .^{[3-5]}$

Fragile $X$ syndrome is caused by mutation of the FMR1 gene on the $X$ chromosome. This site is present at Xq27.3 and the gene spans $39 \mathrm{~Kb}$ containing 17 exons. Mutation is located in the untranslated region of the first exon and is characterized by the presence of an array comprising a repeat sequence of the trinucleotide CGG interspersed with single AGG repeats along its length. The array is polymorphic with respect to the number of CGG repeats it includes as well as the position of the interspersed AGGs. ${ }^{[6,7]}$ The different alleles are usually referred to by the "repeat number" of CGG in the array and this repeat number is the principal determinant of whether an allele is regarded as normal or mutant. Normal subjects have 2 to 50 copies of the repeat and individuals with fragile $X$ syndrome typically have more than 200 of these repeats, a condition known as a full 
mutation (FM). The FM prevents transcription of the FMR-1 gene, resulting in absence of the protein product. In normal transmitting males and female carriers the repeats range from 50 to 199 copies and this intermediate number is known as a premutation (PM). ${ }^{[6]}$ The number of repeats in a PM is potentially unstable and may expand into the FM range. However, this has been observed to take place only during female meiosis. This means that no daughter of a male with a PM would ever be affected but they would be at risk of having a child with FM.

A more distal fragile site, FRAXE located at $\mathrm{Xq}^{28}$ has been associated with amplification of a GCC repeat which is $600 \mathrm{~Kb}$ distal to FRAXA. Normal subjects have 6 to 25 copies of this repeat, whereas subjects with more than 200 copies of the GCC repeat express the FRAXE site. $^{[8,9]}$

Direct analysis of the CGG expansion mutation by Southern blotting has almost replaced the cytogenetic analysis for the laboratory diagnosis of the fragile $X$ syndrome. However, blotting is a relatively expensive and labour intensive procedure, particularly in the context of screening routine referrals for fragile $X$ syndrome, the great majority of whom will be negative. So polymerase chain reaction (PCR) method has been suggested as an ideal alternative technique for screening the referrals and only the seemingly positive cases should be confirmed by Southern blotting method. The aim of this study was to establish the use of PCR based method for initial screening of Fragile $X$ syndrome.

In this study we screened 294 idiopathic mentally retarded patients using PCR method to detect both FRAXA and FRAXE mutations simultaneously and a PCR based assay to detect methylation of the CpG island upstream of the FMR-1 gene in patients with an expanded FRAXA allele.

\section{Materials and Methods}

From the year 1998 to 2002, 294 cases having mental retardation (MR) were referred to Genetics Clinic, AlIMS. After excluding other possible causes all these patients were screened for fragile $X$ syndrome. For each patient a pedigree was drawn and a detailed family history was taken. All patients were examined in detail and a clinical scoring for Fragile X syndrome was done. ${ }^{[10,11]}$

The family was counseled about the genetic testing and an informed consent was taken. $10 \mathrm{ml}$ of blood was collected in EDTA and DNA was extracted using standard phenol-chloroform extraction protocol. ${ }^{[12]}$ The following molecular genetic studies were done:

\section{(i) Duplex Amplification for CGG/GCC Repeats}

Simultaneous amplification of FRAXA and FRAXE triplet repeats was carried out using $100 \mathrm{ng}$ of DNA in $25 \mu$ reaction using 2 pairs of primers, 20 pmole of FXD 5'TGA CGG AGG CGC CGC TGC CAG GGG GCG TGC 3' and FXE 5'GAG AGG TGG GCT GCG GGC GCT CGA GGC CCA 3' for amplification of the FRAXA CGG repeat and 35 pmole of 598 5'GCG AGG AAG CGG CGG CAG TGG CAC TGG G 3' and 603 5' CCT GTG AGT GTG TAA GTG TGT GAT GCT GCC G 3' for amplication of FRAXE CCG repeat as described previously. ${ }^{[13]}$ Taq DNA polymerase buffer $(50.25 \mathrm{mmol} /$ 1 Tris- $\mathrm{HCl}, \mathrm{pH} 8.8,12,45 \mathrm{mmol} / \mathrm{L}\left(\mathrm{NH}_{4}\right)_{2} \mathrm{SO}_{4}, 1 \mathrm{mmol} / \mathrm{L}$ of $\mathrm{Mgcl}_{2}$ and $127.5 \mathrm{ug} / \mathrm{ml}$ and $200 \mathrm{umol} / \mathrm{L}$ of $\mathrm{dATP}$ and dTTP, 150 umol/L dGTP, 50 umol/L 7-deaza-2'dGTP, $10 \%$ dimethyl sulphoxide was used. Hot start procedure was followed i.e. after denaturation at $95^{\circ} \mathrm{C}$ for 10 minutes, $2.5 \mathrm{U}$ of Taq DNA polymerase was added to each tube white maintaining the temperature at $95^{\circ} \mathrm{C}$ for 1 minutes, $64^{\circ} \mathrm{C}$ for 1.5 minutes, $72^{\circ} \mathrm{C}$ for 2 minutes, with a final extension of 5 mintues, at $72^{\circ} \mathrm{C}$. The products were analysed by electrophoresis in a ethidium bromide stained $2 \%$ agarose gel [Figure 1 ].

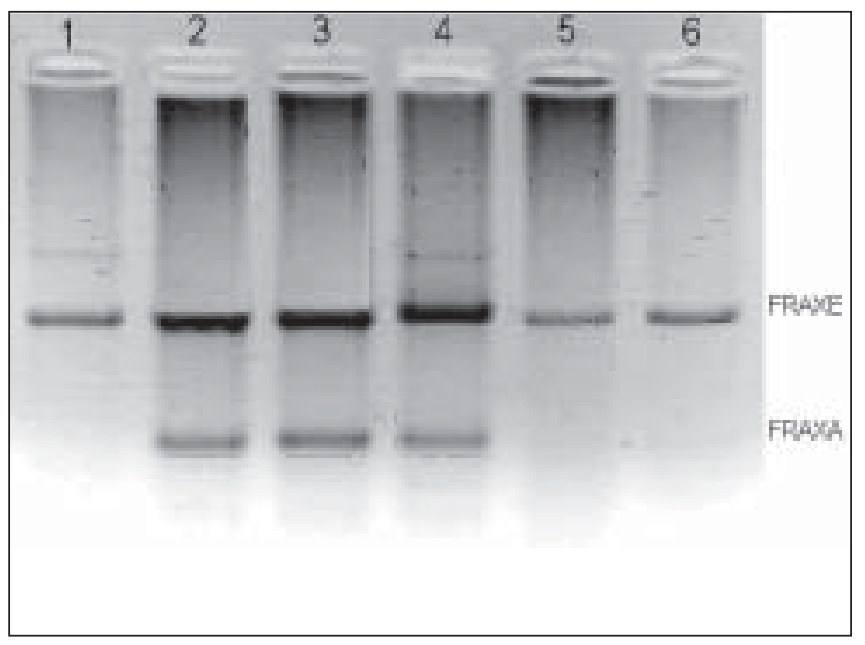

Figure 1: $2 \%$ agarose gel showing amplification products from the FRAXE and FRAXA loci. Lane 2-4 are normal males, lane 1,5 and 6 are males with a FRAXA expansion mutation 


\section{(ii) Methylation Status of FMR-1 Gene}

The CpG island located 5'prime to the FMR-1 gene is not methylated in normal individuals. However, in patients with fragile $X$ syndrome with more than 200 CGG repeats, the $\mathrm{CpG}$ island is methylated and therefore the FMR-1 gene is silenced. The presence of methylation at the FMR1 gene was confirmed using the following protocol. Two tubes each contained with $1 \mu \mathrm{g}$ of genomic DNA, $2 \mu \mathrm{l}$ of 10x restriction endonuclease buffer and $100 \mu \mathrm{l} / \mathrm{ml} \mathrm{BSA}$, in a total volume of $20 \mu \mathrm{l}$ (made up with distilled water) were used. A total of 12 $\mu \mathrm{l}$ of the methylation sensitive enzymes BssHII or Eagl were added to one of the tubes while the other contained no enzyme. The tubes were then incubated at $50^{\circ} \mathrm{C}$ (BssHII) or at $37^{\circ} \mathrm{C}$ (Eagl) overnight. A PCR was then set-up for each of the 2 tubes using the protocol previously described. ${ }^{[13]}$ A PCR was set-up for each of 2 tubes, containing $2 \mathrm{ul}$ of digestion reaction, 20p mol each of the primers FXG 5'AGT GCG ACC TGT CAC CGC CCT TC 3' and FXH 5'GAA ACC ACG TCA CGT GAT CAA CGC TGT TCC 3' and instead of 7'deaza dGTP, $200 \mathrm{umol} / \mathrm{L}$ each of dATP was used. PCR products were analysed on a $2 \%$ Nuseive agarose gel [Figure 2].

\section{(iii) Heterozygosity for normal FRAXA allele}

The samples from females were analyzed for heterozygosity of normal FRAXA allele. The residue of the PCR products were run on a $20 \mathrm{~cm} 10 \%$ non-denaturing polyacrylamide gel for 18 hours at $250 \mathrm{~V}$ in $1 \mathrm{x}$ Tris-borate-

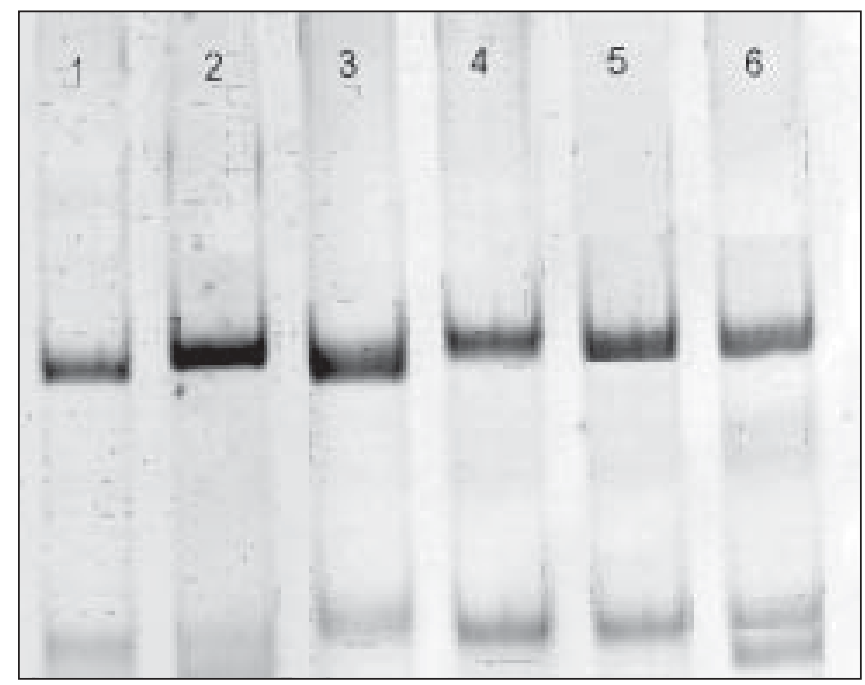

Figure 2: 10\% PAGE showing heterozygosity of FRAXA locus. Lane 1,3,4 and 5 are from females who are homozygous, lane 2 and 6 showing heterozygous females
EDTA buffer for improved resolution of differences of one repeat unit. The gel was silver stained for better specificity using the standard protocol[14] [Figure 3].

\section{(iv) Southern Blotting}

Southern blotting was done for all PCR positive cases and for initial ten PCR negative cases. For FRAXA mutation using double digestion of genomic DNA with Eco RI and Eagl and Southern blots were hybridized with probe pp $2^{[5]}$. Southern blotting was carried out in Dr. B.K. Thelma's lab, South Campus, Delhi University, New Delhi. For Southern blotting random priming technique was used for labeling the probe (pP2) using [a-32p] dCTP. Probe elution was carried out using sephadex G-50 column and after each wash, the column was monitored for radioactivity along the whole tube [Figure 4].

\section{Results}

Out of the 294 cases, 271 were males and 10 females with idiopathic MR. The rest of 13 females were the relatives of the patient (sister(s), mother, mother's sister) who were at high risk of having a PM. Majority of the cases were from North India, few were from other states

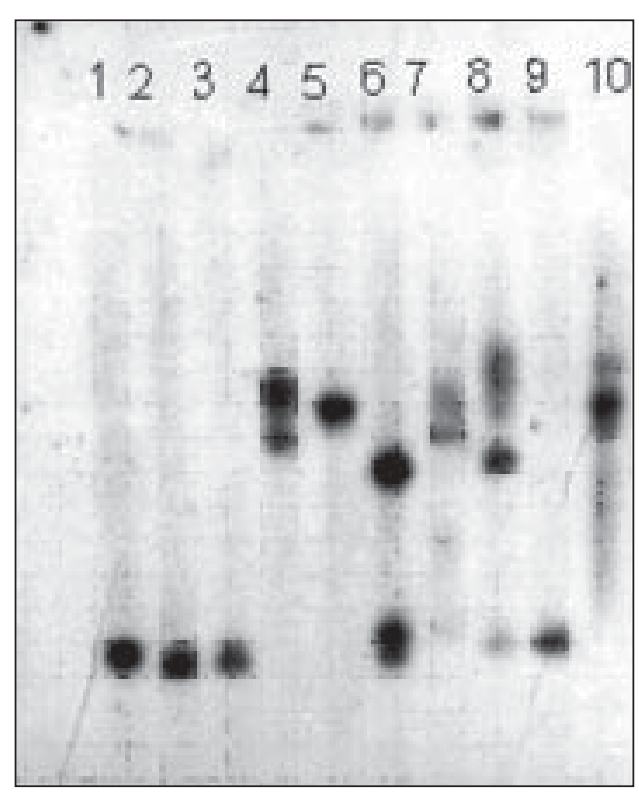

Figure 3: Southern blot analysis of the FRAXA expansion mutation by double digestion of genomic DNA with EcoRI and Eagl and blotting and hybridizing with probe pp2. Lane 1 is normal transmitting male, lane 2,3 and 9 are normal males, lane 4,7 and 10 are FM male with mosaicism, lane 5 is a FM male, lane 6 is a PM female and lane 8 is a FM female 


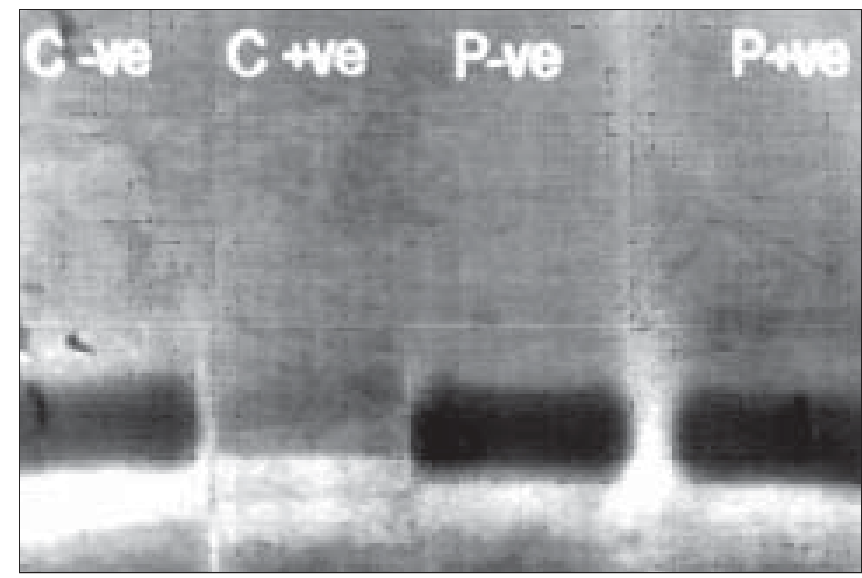

Figure 4: PCR assay for methylation at the FMR-1 gene. Lane 1 and 2 are from normal males and Lane 4 and 5 are patients. $+v e=$ digestion with the methylation sensitive restriction enzyme Eagl; -ve = not digested

of India and two were from neighboring countries. The present data includes 242 cases with no apparent family history, 23 with a positive family history and 16 families having 2 or 3 affected children but without any family history either on the maternal or paternal side. Figure 5 shows a pedigree with a positive family history. The age range of the subjects was 2-22 years (mean age 7.9+ S.D. = 3.98).

All the 294 cases were screened for both FRAXA and FRAXE mutations by PCR approach. About $92 \%$ of routine referrals for Fragile $X$ testing were for male patients and only $8 \%$ were females. We found a total of $36(12.24 \%)$ cases showing FRAXA mutation (FM or

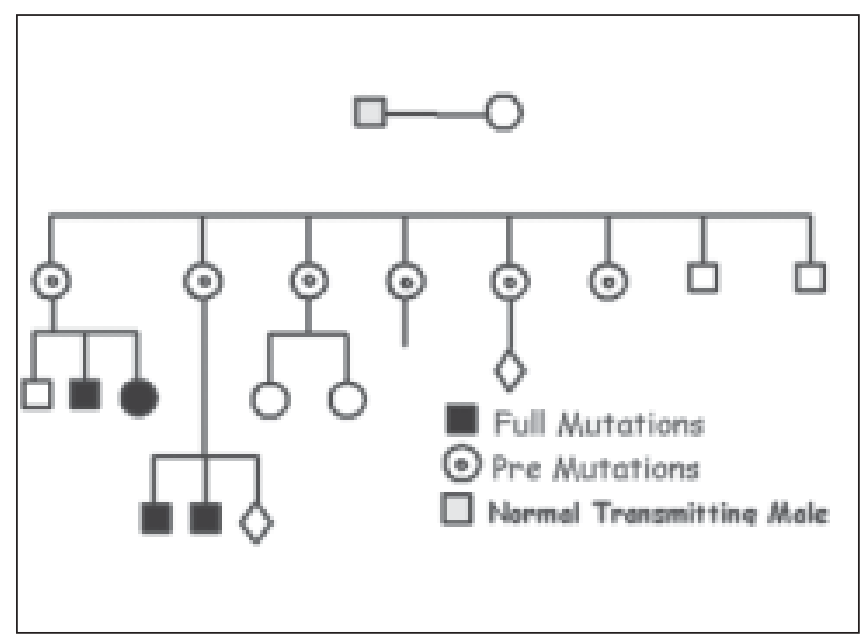

Figure 5: A pedigree showing a normal transmitting male having all daughters with a PM and they further having children with FM. Prenatal diagnosis was done for one of the daughters and the foetus was found to be a normal male.
PM). Out of which $22(7.48 \%)$ males showed expansion of FRAXA allele and $14(4.7 \%)$ of females showed PM and one female showed a FM. [Figure 1] shows amplification products from the FRAXA and FRAXE loci analysed on a $2 \%$ agarose gel. The range of the PCR product of the normal FRAXA allele varied from 74 to $224 \mathrm{bp}$ in length and FRAXE product has a minimum size of $306 \mathrm{bp}$ for an allele with six repeats. We have observed in case of females carrying PM the amplification gets very faint and not reliably detected. But when Southern blotting was done in the same females premutation was observed. Most Frax-A positive cases showed moderate mental retardation and none of the female carriers (PM) had manifestations of syndrome. Only 10 males out of 22 who were Frax A positive had a high clinical score $(\geq 10)$.

In all the 36 positive cases having FM and PM (21 males with FM, 1 female with FM, 1 male mosaic and 13 females with PM) Southern blotting was done for confirmation and a similar result was obtained [Figure 4]. No case was observed with FRAXE mutation in our study.

PCR assay for FRAXA methylation was done for all the 22 fragile $X$ positive males in whom no CGG allele had been detected by PCR. In normal males no product was observed since the site would be unmethylated and hence fully cleaved by the enzyme, except sometimes when a weak signal was retained. But amplification with same intensity was observed in all the male positive cases since the allele would be fully methylated and thus not digested by the methylation sensitive enzyme Eagl and BssHII [Figure 4]. The heterozygosity rate for FRAXA allele in females was $46 \%$. So in case of females if heterozygosity is observed for alleles of normal size it excludes the presence of an expansion mutation.

\section{Discussion}

Fragile $X$ syndrome is recognized as the most common inherited $\mathrm{X}$-linked condition resulting in mental retardation. The disabilities are substantial and therefore early detection is mandatory for reproductive counseling of families in which the fragile $X$ syndrome has been observed.

Cytogenetic method of screening for fragile $X$ has a 
number of technical problems, is more laborious and time consuming but less dependable. This technique has now been replaced by molecular methods. In molecular methods Southern blotting although used widely again has a long laboratory turn round time, is relatively expensive and has got hazards associated with the use of radioisotopes. So PCR method is a rapid and cheap method for initial screening. The best protocol would be to perform PCRs for initial screening followed by Southern blots for confirmation.

Based on an earlier Indian study using Cytogenetic techniques the prevalence of fragile $X(A)$ syndrome has been reported as $1.8 \%$ in patients of both sexes with $\mathrm{MR}, 2.8 \%$ among male patients with idiopathic MR and $5.8 \%$ among subjects with non specific MR using defined clinical criteria. ${ }^{[15]}$ In another study, the frequency of Fragile $X(A)$ syndrome among the idiopathic MR male patients was $6.38 \%$ based on Cytogenetic method and $5.27 \%$ using molecular studies..$^{[3]}$ Yet another Indian study gives a rate of $7 \%$ positivity among unclassified MR cases based on molecular analysis. ${ }^{[4]}$ In 1986, a population study of school children in the city of Coventry gave an overall prevalence of 1/952 in males and females for fragile $X$ syndrome. ${ }^{[16]}$ Later on many of these children diagnosed as having fragile $X$ syndrome based on cytogenetic method were found negative on molecular studies. So in 1997 a revised prevalence figure of $1 / 2720$ males was calculated based on molecular investigations. ${ }^{[17]}$ Another study was conducted in Japanese population in 1994 comparing the Cytogenetic and molecular analysis for fragile $X$ and the results were similar. ${ }^{[18]}$

In our study we screened idiopathic male MR cases without using any clinical scoring system for inclusion, with a positivity rate of $7.48 \%$ which is comparable to previous studies. The results of this study and previous studies re-emphasize the need to evaluate all idiopathic mentally retarded males for fragile $X$ syndrome. It was also evident from our data that clinical scores were not invariably high in Frax positive cases.

Although neither male nor female with a PM has been shown to have reduced IQ, subtle emotional and neurocognitive effects may be present. ${ }^{[19]}$ In half of the females with $F M$ fragile $X$ phenotype have obvious learning disabilities and in about $20 \%$ neurocognitive deficits have been observed. ${ }^{[20]}$ The milder phenotype in females and the variable expression are due to random $X$ chromosome inactivation. The physical features seen in fragile $X$ syndrome are neither specific nor constant. The features also change with time, becoming more apparent as the patient gets older. Western studies have reported a positivity rate between $10.5-14.6 \%$ when clinical screening criteria are used. If no selection criteria are used and all patients with idiopathic MR are tested for fragile $\mathrm{X}$, the reported detection rate ranges from $0.6 \%$ to $14 \% .^{[11,21-23]}$ The present study gives a total detection rate including both the sexes of $12.24 \%$ which is in concurrence with the earlier studies. Considering the significance of positive diagnosis specially with regard to genetic counseling and clinical outcome, screening of all idiopathic MR males should be acceptable. We conclude that PCR based screening for fragile $X$ is reliable and should be used as an initial screening test for all idiopathic mentally retarded males.

\section{Acknowledgement}

We acknowledge the technical help provided by Ms. Monica Tiwari. The authors would also like to thank the Department of Biotechnology (DBT) for the financial assistance.

\section{References}

1. Turner G, Opitz JM, Brown WT. Conference report: Second International Workshop on the Fragile $X$ and on $X$ linked mental retardation. Am J Med Genet 1986;23:1167.

2. Turner G, Webb T, Wake S, Robinson H. Prevalence of Fragile X syndrome. Am J Med Genet 1996;64:196-7.

3. Jain U, Verma IC, Kapoor AK. Prevalence of Fragile $X$ (A) syndrome in mentally retarded children at a genetics referral center in Delhi, India. Indian $\mathrm{J}$ Med Res 1998;108:12-6.

4. Baskaran S, Naseerullah MK, Manjunatha KR, Chetan GK, Arthi R, Rao GV, et al. Triplet repeat polymorphism and Fragile $\mathrm{X}$ syndrome in the Indian context. Indian $\mathrm{J}$ Med Res 1998;107:29-36.

5. Sharma D, Gupta M, Thelma BK. Expansion mutation frequency and CGG/GCC repeat polymorphism in FMR1 and FMR2 genes in an Indian population. Genetic Epidemiol 2001;20:129-44.

6. Verkerk AJ, Pieritti M, Sutcliffe JS, Fu YH, Kuhl DP, Pizzuti $A$, et al. Identification of a gene (FMR-1) containing a CGG repeat coincident with a breakpoint cluster region exhibiting length variation in Fragile $X$ syndrome. Cell 1991;65:905-14. 
7. Kremer EJ, Pritchard M, Lynch M, Yu S, Holman K, Baker $E$, et al. Mapping of DNA instability at the Fragile $X$ to a trinucleotide repeat sequence $\mathrm{p}(\mathrm{CCG}) \mathrm{n}$. Science 1991;252:1711-4.

8. Knight SJ, Flannery AV, Hirst MC, Campbell L, Christodoulou Z, Phelps SR, et al. Trinucleotide repeat amplification and hypermethylation of a $\mathrm{CpG}$ island in FRAXE mental retardation. Cell 1993;74:127-34.

9. Knight SJ, Voelckel MA, Hirst MC, Flannery AV, Moncla A, Davies KE. Triplet repeat expansion at the FRAXE locus and X-linked mild mental handicap. Am J Hum Genet 1994;55:81-6.

10. Turner G, Robinson R, Laing S, Purvis-Smith S. Preventive screening for the fragile $X$ syndrome. $N$ Eng $J$ Med 1986;315:607-9.

11. Laing S, Partington M, Robinson H, Turner G. Clinical screening score for the fragile $X$ (Martin Bell) syndrome. Am J Med Genet 1991;38:256-9.

12. Ausubel FM, Breut R, Kingston RE, et al. (Editors) Current Protocols in Molecular Biology. Greene Publishing Associates and Wiley-Interscience: New York; 1992. p. 1:2.11-2.7.

13. Wang Q, Green E, Bobrow M, Mathew CG. A rapid, nonradioactive screening test for Fragile $X$ mutations at the FRAXA and FRAXE loci. J Med Genet 1995;32:170-3.

14. Wallace AJ. SSCP/Heteroduplex analysis. In: PCR Mutation Detection Procotols. Ed. Theophilus, Bimal DM, Rapley R. Series: Methods in molecular biology Vol. 187. 2002. p. 151-63.

15. Verma IC, Elango R. Fragile X syndrome among chil- dren with mental retardation. Indian $\mathrm{J}$ Pediatr 1996;63:533-8.

16. Webb TP, Bundey S, Todd J. The frequency of the Fragile $\mathrm{X}$ chromosome among school children in Conventry. J Med Genet 1986;23:396-9.

17. Morton JE, Bundey S, Webb TP, MacDonald F, Rindl PM, Bullock S. Fragile $X$ syndrome is less common than previously estimated. J Med Genet 1997;34:1-5.

18. Hofstee $Y$, Arinaml T, Hamaguchi H. Comparision between the cytogenetics test for Fragile $X$ and the molecular analysis of the FMR-1 gene in Japanese mentally retarded individuals. Am J Med Genet 1994;51:46670.

19. Taylor AK, Safanda JF, Fall MZ, Quince C, Lang KA, Hull $\mathrm{CE}$, et al. Molecular predictors of cognitive involvement in female carriers of Fragile $X$ syndrome. JAMA 1994;271:507-14.

20. Mazzocco MM, Pennington BF, Hagerman RJ. The neurocognitive phenotype of female carriers of Fragile $X$ : additional evidence for specificity. J Dev Behav Pediatr 1993;14:328-35.

21. Nolin SL, Snider DA, Jenkins EC, Brown WT, Krawczun M, Stetka D, et al. Fragile X screening in New York state. Am J Med Genet 1991;38:251-5.

22. Brown WT, Jenkins E, Neri G, Lubs H, Shapiro LR, Davies $\mathrm{KE}$, et al. Conference report: Fourth International Workshop on the Fragile $X$ and $X$-linked mental retardation. Am J Med Genet 1991;38:158-72.

23. Hagerman RJ, Amiri K, Cronister A. Fragile X checklist. Am J Med Genet 1991;38:283-7. 